\title{
CHALLENGES IN THE LIVES OF HIV POSITIVE WOMEN
}

\author{
Dr. Madhurima \\ Professor, \\ USOL, Panjab University, \\ Chandigarh, \\ India
}

\author{
Dr. Dilraj Kaur \\ Assistant Professor in Sachdeva College of \\ Education, \\ Punjab, \\ India
}

Article DOI: https://doi.org/10.36713/epra4609

\begin{abstract}
Background: The HIVIAIDS epidemic has gained impetus during the last one and the half decade, expending to all regions of the world and remains to be major global challenge. Recent research has indicated that HIV infection is moving from highrisk populations into the general population. Married, monogamous, heterosexual women belonging to lower strata are highly vulnerable. Women constitute nearly half of world's AIDS population

Aim: The present study attempts to highlight the challenges faced by HIV positive women.

Material and Method: Since HIV/AIDS is a sensitive topic it was decided to undertake a qualitative study so that subterranean aspect of HIV positive women and their circumstances can be analyzed appropriately. Present study was conducted in Ludhiana district, Punjab. A purposive sample of 67 HIV positive woman visiting ART Centre for the treatment was taken. Information was obtained by Interviewing.

Results: The study revealed that stigma and discrimination is the biggest challenge for WLHA as it prevents them from disclosing their HIV status to others and seeking their support. Lack of awareness about HIV also emerged an important challenge for some. There were others who felt that living with HIV has made them physically weak and it affects their working capabilities. Economic instability and dependency of HIV positive women is a big challenge for their survival. HIV positive women do not receive social, emotional and financial support from their parents and in laws. Family members try to maintain distance from these women and hardly come forward to help them. As a result of HIV/AIDS, more women become dependent on fewer income generating family members, thus increasing the already heavy economic burden experienced by families.

Conclusion: The study implicates that WLHA face more challenges than men with HIV because of their lower position in society. Due to their lack of awareness they contract HIV infection unknowingly. This lifelong infection affects their physical and psychological health. WLHA are stigmatized and labeled for their immorality due to their illness and they face discrimination from family members, health care workers, colleagues, clients and their own community members.
\end{abstract}

KEYWORDS: Stigma, Support, Challenges, HIV positive women

\section{INTRODUCTION}

Women now make up nearly half of all people living with HIV worldwide. In 2005 women represented 26 percent of HIV/AIDS diagnoses, compared with 8 percent in 1985 (UNAIDS, 2005). The major source of infection is through heterosexual transmission and women are at a biological disadvantage in contracting HIV. In every society, there are individuals and population groups who are more vulnerable than others are. In all cultures, certain categories of girls and women face strong social pressures that can render them more vulnerable to HIV. Brettle and Lean (1991) and Fletcher (1990) reported that women are highly vulnerable to HIV socially and physiologically. UNAIDS (2009) stated that 90 percent of 1.7 million women infected with HIV are in Asia who gets infection from their husbands with whom they have been in relationship for long time. Lee et al. 
(2009) examined the dynamics of HIV transmission in heterosexual couples and found that a majority of these HIV positive women got the infection from their partners. Santhya and Jejeebhoy (2007) reported that married young women fall in high risk because of their exposure to regular unsafe sex within marriage. High risk behaviour of husbands before and within marriage behavior makes wives vulnerable. According to Morrison (2006) housewives form a larger pool of individuals who are at greater risk of HIV primarily through their husbands. He reported that sex workers are no doubt at risk of HIV/AIDS but it is the non-sex worker i.e. housewives who are at greater risk of HIV primarily through their husbands. According to Raj et al. (2013) 90 percent of new infections in Indian women do not involve sex-work. Instead these new infections result from matrimonially sanctioned sexual relations (Vlassoff et al. 2013). Additionally, low knowledge and awareness about HIV make these women vulnerable. According to Dube (2000) woman is thought to be indecent if she seeks information about sexuality and sexually transmitted infection. She cannot ask her partner to use condom even if she fears of getting infection with AIDS or STDs. The economic dependency on men is also one of the factors contributing to spread of HIV among women. Gender inequalities and the low status of women limit their access to resources. Women feel powerless and unable to protect themselves as they are in no position to negotiate safe sex within or outside of marriage.

Researchers have pointed out that women tend to experience greater stigma and discrimination than men, are more likely to experience its harshest and most damaging forms, and have fewer resources for coping with it (Liamputtong et al. 2009; Paxton et al 2005).Women living with HIV/AIDS are very frequently referred to as 'vectors', 'diseased' and 'prostitutes', but these terms are seldom used with infected men (Dixit, 2005; Ndinda et al. 2007; UNICEF, 2005; Stein and Kuhn, 1996).

HIV/AIDS is among the diseases which not only affects the physical aspects, but also the social and psychological conditions of the patients. In addition to the physiological effects of the disease, WLHA may encounter numerous problems such as discrimination, losing social status and role, changes in the patterns of relationships (intimacy), losing jobs and financial resources etc. Discrimination in the form of neglect, isolation, verbal abuse is reported by a large number of women in both urban and rural areas. HIV-positive widows face double burden of stigma. They face discrimination from the family and the society. They not only have to bear the grief of the death of their husbands, and economic repercussions, but also have to face the stigma attached to HIV, take care of their own health and the health of children who may be positive. Many of these problems are also common among other people who suffer from other chronic diseases, but the stress associated with social and family problems arising from the diseases such as social stigma and exclusion affect WLHA to a large extent. Family members are frightened to take care of HIV/AIDS patients, especially if she is a woman.

Researchers indicate that people experience various short and long-term emotional and behavioural reactions immediately after being diagnosed with HIV such as shock (Amuyunzu-Nyamongo et al., 2007); surprise and disbelief (Hult et al., 2009); anger (Reeves et al. 1999); denial (Pittiglio \& Hough, 2009); fear (Medley et al., 2009; Reeves et al., 1999); guilt and bereavement (Holt et al., 1998) etc. According to Joseph and Bhatti (2004), HIV-positive wives of positive men mostly adopt escape-avoidance coping strategies. According to Ajibade et al. (2016) religion plays a vital role in the care of HIV infected persons and their families. In the light of these facts perception of WLHA about the challenges faced by them and coping mechanisms used by them have been explored.

The present study focuses on the following two objectives:

1. To explore different types of challenges faced by women living with HIV/AIDS;

2. To identify the coping mechanisms used by these women living to deal effectively with these challenges.

\section{METHOD AND TECHNIQUE}

For the present study, research design is partially exploratory and partially descriptive in nature. A sample of 67 WLHA visiting ART Centre in Lord Mahavir Civil Hospital, Field Ganj Road, Ludhiana district of Punjab was collected. HIV positive women in the age group of 15-60 years constituted unit of analysis. Theoretical sampling method was used. In theoretical sampling, the factor that determines the size of the sample is often 'saturation': information becomes repetitive and confirmatory, and no new information is derived from fresh interviews. WLHA visiting ART Centre were interviewed at length using Interview guide.

\section{RESULTS}

The study sample consisted of 67 WLHA, 29 respondents were in the middle age group i.e. 35-45 years. There were 18 respondents whose age was between 25-35 years. There were nine respondents in the age group of 15-25 years. There were seven 
respondents in the age group of 45-55 years and four respondents who were above the age of 55 years.

With regard to marital status it was found that only five respondents were unmarried, remaining 62 had once married. There was one respondent who became widow at the age of 19 years; there were 17 respondents who got widowed when they were in the age group of 20-30 years. There were 16 respondents who became widows in age group of 30-40 years and remaining four respondents became widows in age group of 40-50 years. There were 14 married respondents living with their husbands. There were 43 respondents who belonged to Sikh religion. The present study is based in Ludhiana district of Punjab which is a Sikh dominated state. The second highest number was of Hindu respondents i.e. 22. There was one respondent who was a Christian and one was from a Muslim community who were detected HIV positive. With regard to caste background, out of 67 respondents, there were 39 respondents who belonged to General category and remaining 28 belonged to reserved category.

16 respondents were illiterate and seven respondents were educated up to primary level. There were 17 respondents who had education up to middle level only. Some of them didn't pass the 8thstandard due to lack of encouragement from parents. There were 13 respondents who were matriculate and 11 respondents had education up to plus 2 level. There were only three respondents who were graduates. 35 respondents were not doing any type of paid job, 12 of them were married and totally dependent on their husbands. There were nine respondents who were widows, five of them were living with their parents and two were living with their in laws, two of these were living with their sons (both in rural area) after the death of their husbands. These 35 respondents also include four students and one respondent who were in prison. There were 15 respondents who were in service and six of these respondents were working in health care centers on contract basis. There were two respondents who were graduates and working as school teachers. One respondent was a staff nurse in a Government hospital. There was one respondent who was working as a housekeeper in a mall. Two respondents were workers in factories and one respondent worked as a machine operator. Nine respondents were housemaids. Five respondents were self-employed, four of them had their own boutique and one was running a beauty parlour from her residence. Three respondents were included in others category, one was an orchestra dancer and two were female sex workers.

Findings with regard to income of the respondents show that there were 36 respondents in the low income group. A large number of respondents in the present study were poor, either they had no source of livelihood or were earning very minimal amount. Out of 67, 26 respondents admitted that they had no income, it included 12 married housewives who were dependent on their husbands, nine widows - five of them were dependent on their parents, two were dependent on their in laws, and two were dependent on their sons. This category also included four students and one prisoner. Nine housewives had agriculture income. Five factory workers, one Asha workers, one Anganwari worker, four paramedical staff, two school teachers, three self-employed, one Orchestra dancer and two female sex workers were earning up to Rs 15,000/- per month. There were three respondents, a widow of an army jawan who was getting pension along with her salary and another widow of an army jawan was getting pension along with income from agricultural land. Another respondent was earning more than Rs. 15000/- per month from her parlour. In high salary group, there were includes only two respondents, one of them was a staff nurse and another had a large agricultural land.

Table no 1 Distribution showing Challenges for Women living with HIV/AIDS

\begin{tabular}{|l|l|}
\hline Response & No. of Respondents \\
\hline Lack of Awareness & $\mathbf{4 1}$ \\
\hline Health Issues & $\mathbf{3 1}$ \\
\hline Issues of disclosure of HIV/AIDS & $\mathbf{2 8}$ \\
\hline Stigma and Discrimination & $\mathbf{4 2}$ \\
\hline Lack of Support & $\mathbf{3 7}$ \\
\hline Economic Challenges & $\mathbf{3 2}$ \\
\hline Increased Vulnerability of Children & $\mathbf{2 1}$ \\
\hline Lack of Awareness \& Health Issues & $\mathbf{3 1}$ \\
\hline Stigma and Discrimination \& Lack of Support & $\mathbf{3 7}$ \\
\hline Economic Challenges \& Increased Vulnerability of Children & $\mathbf{2 1}$ \\
\hline
\end{tabular}


HIV positive women mentioned different challenges faced by them. Out of 67 respondents 42 respondents felt that stigma and discrimination is the biggest challenge for them as it prevents them from disclosing their HIV status to others and seeking their support. There were 41 respondents who admitted that lack of awareness about HIV as important challenge. For 37 respondents lack of support is the big challenge for women living with HIV. Eight respondents whose children were tested HIV positive blamed their lack of awareness for infecting children from the disease. For 31 respondents health issues is major challenge faced by WLHA. For 28 respondents the disclosure of HIV status to others is the major challenge. For 21 respondents vulnerability of children for WLHA is a big challenge. There were 31 respondents who felt lack of awareness and health issues both were major challenges for WLHA. For 37 respondents both stigmadiscrimination and lack of support were important challenges that WLHA face. For 21 respondent's stigma and discrimination, economic challenges and increased vulnerability of children were the challenges for WLHA. Such findings indicate that stigma and discrimination as well as lack of support were the major challenges faced by women suffering from HIV/AIDS.

There were 41 respondents who admitted that lack of awareness about HIV is the biggest challenge faced by HIV positive persons. It also included 23 respondents who were not aware of HIV/AIDS and its mode of transmission. These 23 respondents were illiterate, it included 15 widows, five married respondents, one remarried respondent, one unmarried respondent and one divorced respondent. There were 18 respondents who admitted that they had knowledge about HIV but on further probing they gave wrong responses. It included ten widow, six married respondents and two remarried respondents. Respondents reported that they would have safeguarded themselves if they had knowledge about HIV. Respondents who had contracted HIV through infected syringes and blood admitted that it was their lack of awareness about modes of transmission that they became HIV infected. It included two respondents who were infected through blood transfusion i.e. one married respondent and one divorced respondent whose husbands were tested HIV negative; two were infected through HIV infected syringe during treatment. According to them proper awareness about mode of transmission could have saved them.

Results show that there were 11 respondents who felt that HIV infection affects the physical health of a person and lessens her capability of doing any work. It included seven widows, three married respondents and one deserted respondent. These respondents reported that they themselves feel physical deterioration of health as they were not able work efficiently after getting HIV as they used to do earlier. They feel tired and weak due to their illness. In spite of poor health these women have to do all household chores and take care of other family members. In addition to physical health, some respondents reported deterioration in mental health.

Out of 32 respondents who reported economic challenge as one of the biggest challenge, 27 respondents were economically dependent on their husbands, their parents, in laws and relatives and seven of them had HIV positive children. There were two married FSWs, three housemaids one divorced and two widows who were working. Such findings clearly indicate economic dependency faced by WLHA forces them to indulge in high risk behaviour. Lack of skill to be actively engage in productive work, their HIV status and those of their children makes them vulnerable to poverty and abuse. The respondents who were living with their in laws after the death of their husbands and could not go to their natal family because they had no support from them. They compromised with the situation and finally decided to live with their in laws to get financial help for children and for themselves. Although most of them were blamed for killing their husbands and their integrity was questioned but they kept mum because of their economic dependency on their in laws. Family members try to maintain distance from these women and hardly come forward to help them. The death of husbands who were the sole earner in the family makes these women economically weak. These single mothers face financial difficulties in meeting even the day to day expenses of running a home.

Stigma and discrimination faced by WLHA emerged as one of the biggest challenges. There were 41 respondents who faced discrimination and stigma by their own families. Their life changed after they were found to be HIV positive, the behaviour of their family members changed towards them. It included 27 widows who were stigmatized and discriminated for their illness by their in laws, seven married and two remarried respondents were discriminated by their husbands, two unmarried respondents were ill-treated by their father, one divorced and two widow respondents were discriminated by their parents and siblings. The lack of necessary HIV-related knowledge and skills in communicating about sensitive topics (e.g., sexual behaviours and HIV transmission) can be also a barrier in acceptance of HIV positive woman in our society. There were 24 respondents who faced physically discrimination from their family members. 
Most of these were physically discriminated by their in laws. It included seven respondents who were thrown out of husband's house by in laws, two unmarried respondents whose father ill-treated them, five widows who were not allowed to enter the kitchen, four widows who were given separate utensils by in laws, three married respondents who were physically abused by their husbands, three married respondents were asked to live in a separate house with their husbands. Violence is a particularly harsh form of discrimination faced by women. Women and girls report increased violence for requesting condom use, accessing voluntary testing and counselling, refusing sex within or outside marriage, or for testing HIV positive. There were 41 respondents who were psychologically discriminated by their family members. It included 26 respondents who were living with their in laws i.e. 18 widows and eight married respondents. They were blamed as being woman of loose character by their in laws. It also included seven respondents i.e. five widows and two divorced respondents who were living in parental family. They were sometimes psychologically discriminated by their sisters in law. It included four widows, three married and one remarried respondent who faced psychological discrimination from their in laws. Moreover, women were often blamed by their in-laws for infecting their husbands by

not controlling their husbands" urges to have sex with other women. There were 39 respondents who faced economic discrimination from their family members. Most of these respondents were widows and not engaged in any paid work, they had no money for their basic needs. Seven women were asked to leave the house of their in-laws after their husbands died and denied their inheritance. There were two respondents who faced sexual discrimination by the close relatives in husband's family. There were 34 respondents who faced social discrimination; they were socially ostracized by their family and relatives. These respondents were not invited in family functions by their relatives fearing they would also get stigmatized if they interacted with them.

\section{COPING MECHANISMS USED BY WOMEN LIVING WITH HIV/AIDS}

HIV is a lifelong condition and it needs various physical as well as emotional readjustments to make life easy and less stressful. Coping with HIV becomes a challenge in these women's lives. An attempt has been made to procure information about coping mechanisms used by these women to cope with their illness.

Table no 2 Distribution showing Coping mechanisms used by Women living with HIV/AIDS

\begin{tabular}{|l|c|}
\hline Coping Mechanisms & No. of respondents \\
\hline Keeping busy in household chores & 35 \\
\hline Meditation and Prayers & 25 \\
\hline Avoiding & 23 \\
\hline Denial and Rejection & 12 \\
\hline Non-disclosure & 37 \\
\hline
\end{tabular}

Results show that there were 35 respondents who kept themselves busy in household chores so that they don't get time to think about their disease all time. It included 23 widow respondents and ten married respondents and two unmarried respondents. There were 25 respondents who keep themselves busy in meditation and prayers to get strength and peace. It included 14 widows, eight married respondents, two divorced respondents and one deserted respondent. There were 23 respondents who adopted the avoidance method to minimize stigmatized comments from family and community which included 12 widows and six married respondents who were living with their in laws and five widow respondents who were living with their parents. There were 12 respondents who used denial and rejection as a coping mechanism as they don't want disease to overpower their lives and become an obstacle to live their lives normally.

\section{DISCUSSION}

HIV affects the physical, psychological, economic and social life of WLHA. In society WLHA are not accepted but discriminated, blamed and humiliated due to their illness. This is the reason people are reluctant to disclose about this disease. WLHA were shocked, hurt, cried and denied when they were tested positive for HIV positive report and people's perception about them restrict them to live their normal life. People's judgmental attitude toward PLWHA makes them aware about the reason behind it. The care for children and family members encourages them to repress the stress and all negative thoughts come to their mind. There WLHA try to cope with the problem and they opt for different coping mechanism as per their needs and circumstances. Women whether married or single, divorced or widowed, sex workers or migrants are most susceptible to the negative impacts of HIV and AIDS due to both biological and cultural 
reasons. Research has proven that women are biologically more prone to HIV infections than men. Further, cultural factors place them in lower position and they are not able to safe guard themselves against infection whether she is a sex worker or housewife. WLHA along with illness carry the stigma of HIV/AIDS as these women are considered to be carrier of infection. There is a common perception in society that WLHA deserve their HIV positive status because they have done something ,wrong". Stigma and discrimination does not only make it difficult for these women to cope with their illness on a personal level, but it also interferes with attempts to fight the AIDS epidemic as a whole. WLHV face stigma and discrimination in the family, in health care system, and work place. Parents and in-laws are not ready to keep them; left with no alternative they live a life of misery and agony. HIV positive women keep themselves busy in household chores or meditation so that they don't get time to think about their disease and problems associated with it. For majority of women it is their survival which important rather than the stigma attached to PLWHA.

WLHA try to cope with the problem and they opt for different coping mechanism as per their needs and circumstances. Results corroborate the findings of Neves \& Gir (2006) and Lazarus \& Folk man (1984) that coping helps WLHA to live their life positively with the disease and reduces stress. Results also support the findings of Faria \& Seidl (2006) and Temoshok \& Chandra (2000).

\section{REFERENCES}

1. Ajibade, B.L,Oseni, R.E,Akinpelu, A.O(2016) Perceived Psychosocial Impacts of Stigmatization and Coping Styles amongst People Living with HIV/AIDS (PLWHA) in Selected Hospitals, Abeokuta, Ogun State, Nigeria. Journal of Natural Sciences Research, 6(8): 68-79.

2. Amuyunzu-Nyamongo, M., Okeng'o, L., Wagura, A., \& Mwenzwa, E. (2007). Putting on a brave face: the experiences of women living with HIV and AIDS in informal settlements of Nairobi, Kenya. AIDS care, 19(sup1), 25-34.

3. Brettle, R. P. \& Leen C. L. S. 1991.The natural history of HIV in women, AIDS. 5(11):1283-1292.

4. Dixit, A. P. 2005. Global HIVS/AIDS Trends. Delhi: Vista International Publishing House.

5. Dube, S.2000. Sex, Lies and AIDS. New Delhi: Harper Collins press, India.

6. Fletcher, S. H. (1990). AIDS and women: An international perspective. Health care for women international, 11(1), 33-42.

7. Holt, R., Court, P., Vedhara, K., Nott, K. H., Holmes, J., \& Snow, M. H. (1998)The role of disclosure in coping with HIV infection. AIDS care, 10(1), 49-60.

8. Hult, J.R., Maurer, S.A., \& Moskowitz, J.T. (2009) I'm, sorry, you're positive: A qualitative study of individual experiences of testing positive for HIV. AIDS Care, 21(2), 185-188.

9. Joseph, E. B., \& Bhatti, M. R. S. (2005). Psychosocial problems and coping patterns of HIV seropositive wives of men with HIV/AIDS. Social work in health care, 39(1-2), 29-47.

10. Lee, Jin-Hee, Eun-ju Lee, Sung Soon-Kim, JeongGu Nam, Jiyoung Whang and Mee-Kyung Kee. 2009. Epidemiological Characteristics of HIVInfected Women in the Republic of Korea: A Low HIV Prevalence Country'. Journal of Public Health Policy, 30(3): 342-355.

11. Liamputtong, P., Haritavorn, N., \& KiatyingAngsulee, N. (2009). HIV and AIDS, stigma and AIDS support groups: Perspectives from women living with HIV and AIDS in central Thailand. Social Science \& Medicine, 69(6):862-868.

12. Medley, A. M., Kennedy, C. E., Lunyolo, S., \& Sweat, M. D. (2009). Disclosure outcomes, coping strategies, and life changes among women living with HIV in Uganda. Qualitative health research, 19(12), 1744-1754.

13. Morrison, L. (2006). It's in the nature of men': Women's perception of risk for HIV/AIDS in Chiang Mai, Thailand. Culture, health \& sexuality, 8(2): 145-159.

14. Ndinda, C., Chimbwete, C., Mcgrath, N., Pool, R., \& MDP GROUP. (2007). Community attitudes towards individuals living with HIV in rural KwaZulu-Natal, South Africa. AIDS care, 19(1): 92-101.

15. Paxton, S., G. Gonzales, K. Uppakaew , K. K. Abraham, S. Okta, C. Green, K. S. Nair, T. Parwati Merati , B. Thephthien, M. Marin \& A. Quesada. 2005. AIDS-related discrimination in Asia. AIDS Care: Psychological and Socio-medical Aspects of AIDS/HIV, 17(4): 413-424.

16. Pittiglio, L., \& Hough, E. (2009). Coping with HIV: Perspectives of mothers. Journal of the Association of Nurses in AIDS Care, 20(3), 184-192.

17. Raj A, Saggurti N, Battala M, Nair S, Dasgupta A, et al. (2013) Randomized controlled trail to test the RHANI wives HIV intervention for women in India at risk for HIV from husbands. AIDS Behavior. 17(9): 3066-3080.

18. Reeves, P. M., Merriam, S. B., \& Courtenay, B. C. (1999). Adaptation to HIV infection: The development of coping strategies over time. Qualitative Health Research, 9(3), 344-361.

19. Santhya, K.G.\& Jejeebhoy, Shireen J. 2007. Early Marriage and HIV/AIDS: Risk Factors among Young Women in India. Economic and Political Weekly, 42(14): 1291-1297.

20. Stein and Kuhn, 1996). Stein, Z. A., \& Kuhn, L. (1996). HIV in women: What are the gaps in knowledge? In Jonathan M. Mann and Daniel J.M. 
Tarantola (eds) AIDS in the world II: global dimensions, social roots, and responses. The Global AIDS Policy Coalition, New York, Oxford University Press.

UNAIDS (2005). Intensifying HIV prevention: policy position paper. UNAIDS, Geneva. August 2005.

Available

at

https://www.unodc.org/documents/hiv-

aids/Intens.prevention.pdf

22. UNAIDS, 2009. Report on the global AIDS epidemic. UNAIDS, Geneva: Available: https://www.unaids.org/en/.../2009/20091124_jc17 00_epi_update_2009_en.pdf

UNICEF (2005). The state of the world's children 2006: excluded and invisible. Available at https://www.unicef.org/publications/index_30398.ht $m l$

24. Vlassoff, C., Weiss, M. G., \& Rao, S. (2013). A question module for assessing community stigma towards HIV in rural India. Journal of biosocial science, 45(3): 359-374. 